\title{
The role of mitochondrial genome in essential hypertension in a Chinese Han population
}

\author{
Hai-Yan Zhu ${ }^{1,2}$, Shi-Wen Wang ${ }^{1}$, Lisa J Martin ${ }^{3}$, Li Liu ${ }^{4}$, Yan-Hua Li ${ }^{1}$, Rui Chen ${ }^{1}$, Lin Wang ${ }^{1}$, \\ Min-Lu Zhang ${ }^{5}$ and D Woodrow Benson*,3
}

${ }^{1}$ Division of Geriatric Cardiology, General Hospital of Chinese PLA, Beijing, China; ${ }^{2}$ Emergency Department, General
Hospital of Chineses PLA, Beijing, China; ${ }^{3}$ Cardiology Division, Cincinnati Children's Hospital Medical Center,
Cincinnati, OH, USA; ${ }^{4}$ Department of National Center for Cardiovascular Disease, Chinese Academy of Medical
Sciences, Beijing, China; ${ }^{5}$ Department of Computer Science, University of Cincinnati, Cincinnati, OH, USA

Earlier genetic studies of essential hypertension have focused on nuclear genes or family-based mitochondrial screening in Caucasian and African-American pedigrees. The role of mitochondria in sporadic Chinese hypertensives is unknown. We sequenced mitochondrial genomes in 306 age- and gender-balanced Chinese Han hypertensives and controls. In 153 hypertensives, putative functional changes included 4 changes in rRNA genes, 11 changes in $t R N A$ genes and 25 amino-acid substitutions. The remaining variants were synonymous changes or non-coding regions. In the 153 controls, 2 base changes in the $t R N A$ genes and 13 amino-acid substitutions were found. A8701G in ATP6 gene (belongs to haplogroup $M ; P=0.0001$ ) and C8414T in ATP8 gene (belongs to haplogroup $D ; P=0.01$ ) were detected significantly different in the cases and controls. Interestingly, the cases were more likely to have two or more amino-acid changes and RNA variants compared with the controls (57.43 versus $\mathbf{2 3 . 8 1 \% , P}=\mathbf{0 . 0 0 0 1 )}$. In addition, several variants we found were highly conserved and/or specifically located at the $3^{\prime}$ end adjacent to the anticodon, which may contribute to the stabilization of structure, and thus lead to the decrease of tRNA metabolism. In conclusion, mitochondrial SNPs (mtSNPs) may affect the course of hypertension in sporadic Chinese hypertensives. Some specific mtSNP within mitochondria may have potential role in the Chinese hypertensives due to their function. Synergetic interaction between mitochondrial mtSNPs and/or haplogroups is needed to be investigated in the future.

European Journal of Human Genetics (2009) 17, 1501-1506; doi:10.1038/ejhg.2009.63; published online 29 April 2009

Keywords: essential hypertension; mitochondria; haplogroup

\section{Introduction}

Hypertension is a common condition, a risk factor for heart disease, renal failure and stroke, affecting approximately 1 billion individuals worldwide and 160 million in China. ${ }^{1,2}$ Thus, understanding the underlying etiology of hyper-

*Correspondence: Dr DW Benson, Cardiology Division, MLC 7042 Cincinnati Children's Hospital Medical Center, 3333 Burnet Avenue, Cincinnati, Ohio 45229 , USA.

Tel: + 1513636 7716; Fax: + 1513636 5958;

E-mail: woody.benson@cchme.org

Received 22 July 2008; revised 2 March 2009; accepted 12 March 2009; published online 29 April 2009 tension has been a major research focus, especially the genetics of hypertension. Indeed, as the completion of the draft sequence of the human genome, geneticists have announced that within 10 years, they expect to determine the significance of the genome as related to essential hypertension. ${ }^{3}$ Some progress has been made. For example, for systolic blood pressure alone, 27 nuclear loci have been identified in populations of European and African ancestry. ${ }^{3}$ However, to date, no consistent results have been obtained across ethnicity and races supporting the need for genetic studies in diverse populations. $^{4-8}$ 
Although the nuclear genome has been studied extensively with respect to hypertension, much less work has been carried out with the mitochondrial genome (mtDNA). Yet, there is evidence to suggest that mitochondria and mtDNA may be important in hypertension. For example, mitochondria produce reactive oxidative species (ROS), and these ROS can cause hypertension. ${ }^{9-11}$ With respect to the evidence of mtDNA, a hallmark of involvement of mtDNA is maternal inheritance. Multiple studies have identified strong maternal inheritance of blood pressure, with one study suggesting that over one-third of hypertension could be attributed to mtDNA variation. ${ }^{12-14}$ Interestingly, a variant in mitochondrial tRNA $^{\text {Ile }}$ has been identified in a single family, which segregated with hypertension and appeared causal. ${ }^{15}$ Taken together, this study suggests the importance of looking at mtDNA variation to further our understanding of the underlying etiology of essential hypertension.

Thus, our objective was to determine the relationship between mtDNA variation and essential hypertension. We carried out a systematic and extensive screening of mitochondrial genes at the Institute of Geriatric Cardiology, Chinese People's Liberation Army (PLA) General Hospital and Cincinnati Children's Hospital Medical Center in a Chinese cohort. We focused on this Chinese Han population because of the high morbidity of essential hypertension in Chinese adults (nearly $11.8 \%)^{2}$ and the limited amount of research on this racial group. We used a population instead of family-based strategy for two reasons: (1) large numbers of hypertensives without family history are not detected in China, and they might be overlooked for lacking of medical knowledge and regular checks and (2) the morbidity of essential hypertension is not totally family-based; $50-60 \%$ of hypertensives are sporadically distributed. ${ }^{2}$

\section{Methods \\ Patients}

We evaluated 153 individuals with hypertension; all participants were (1) Beijing residents who were outpatients or in-patients at the Institute of Geriatric Cardiology, Chinese PLA General Hospital from January 2006 to January 2007; (2) older than 18 years old; (3) diagnosed as primary hypertension;and (4) none of the patients were receiving antihypertensive medication. Exclusion criteria: Participants were diagnosed as (1) secondary hypertension (primary aldosteronism, renal arterial sterosis, aortic coarctation, and so on); (2) congenital heart diseases; and (3) organic valve diseases. All participants were Han Chinese evaluated and underwent a thorough examination, including medical record review, clinical evaluation, echocardiographic scanning, biochemical assay as well as genetic analysis. The protocol was approved by the Ethics Committee of Chinese PLA General Hospital and Institute
Review Board of Cincinnati Children's Hospital Medical Center; all participants gave written informed consent. Controls were healthy Beijing residents who accepted annual checkup in Chinese PLA General Hospital from January 2006 to January 2007. None of the control subjects had a family history of hypertension, and all had a systolic BP (SBP) of $<130 \mathrm{mmHg}$ and a diastolic BP (DBP) of $<85 \mathrm{mmHg}$.

\section{Patient assessment}

Weight and height were measured while the subjects were fasting overnight and wearing only underwear. Blood pressure was measured in triplicate by a single physician who was expert in the evaluation of hypertension, with an appropriate arm cuff and a mercury sphygmomanometer with the subject in sitting position after 5 min rest. The arithmetic mean of the last two measurements was calculated. Korotkoff phase I was taken for SBP and V for DBP. Hypertension was defined as SBP $\geq 140 \mathrm{~mm} \mathrm{Hg}$ or DBP $\geq 90 \mathrm{~mm} \mathrm{Hg}$ on 3 consecutive day according to the Seventh Report of the Joint National Committee. ${ }^{1}$ After 12-h fast, $4 \mathrm{ml}$ venous blood was drawn to test biochemical assays, including fasting blood sugar, total cholesterol, triglyceride, high-density lipoprotein, low-density lipoprotein, blood urea nitrogen, urea acid and creatinine by automatic biochemistry analyzer (Hitach 7600DDP, Japan), using Roche biochemical reaction kits.

\section{Mitochondrial DNA analysis}

DNA was isolated from whole blood using Promega Wizard Genomic DNA Purification Kit (Madison, WI, USA), The hottest spots of cardiovascular diseases ${ }^{16}$ were screened using oligodeoxynucleotides 3150-3600, 3796-4654 and 7937-8797 bp, purified and subsequently analyzed by direct sequencing in an ABI 3700 automated DNA sequencer, using the BigDye Terminator Cycle sequencing reaction kit, and analyzed with SeqWeb program GAP(GCG) according to the updated consensus Cambridge sequence. ${ }^{17}$

The primers are as follows: 3243F:5'-AGGACAAGAGAAA TAAGGCCT-3', 3243R:5'-TAAATAGGAGGCCTAGGTTG-3', 6F:5'-TGCTCCTTTAACCTCTCCA-3'， 6R:5'-AAGGATTATG GATGCGGTTG-3', 12F:5'-ACGAGTACACCGACTACGGC-3' and 12R:5'-TGGGTGGTTGGTGTAAATGA-3'.

\footnotetext{
Statistical analysis

Comparison of the cases and controls, continuous variables are expressed as mean \pm SD. Discrete variables in groups are expressed as frequency. Relations between continuous variables were assessed by $t$-test. And discrete variables were analyzed by Pearson's $\chi^{2}$-test.

To determine whether the cases and controls differ with respect to mtDNA variation, we used logistic regression to determine the chance of having hypertension for subjects with gene variants versus those without adjusting for age,
} 
gender or more variables, including heart rate and body surface area.

All the statistical analyses were carried out using the software Stata 7.0 (StataCorp, College Station, TX, USA) and SAS 9.1 (SAS Institiute, Carey, NC, USA).

\section{Results}

\section{Clinical evaluation}

Descriptive information for the 153 age- and genderbalanced casesand controls is provided in Table 1 . The average age $(52.06 \pm 4.84$ versus $50.99 \pm 15.96$ years, $P=0.43$ ), gender (54 versus $54 \%, P=1$ ), body mass index $(24.32 \pm 2.20$ versus $24.04 \pm 3.03, P=0.36)$ of the cases is similar to the controls. In the cohort, more hypertensives smoke and drink, and hypertensives have higher lowdensity lipoprotein and creatinine than normotensives.

\section{Analysis of mitochondrial sequence variants}

A list of pathogenic variants was taken from MitoMap (http://www.mitomap.org/) and a list of polymorphisms from mtDB (http://www.genpat.uu.se/mtDB/). ${ }^{18,19}$ In the 153 hypertensives, putative functional changes included 4 changes in $r R N A$ genes, 11 changes in $t R N A$ genes and 25 amino-acid substitutions. The remaining variants were synonymous changes or non-coding regions (Table 2). In the 153 controls, 2 base changes in the $t R N A$ genes and 13 amino-acid substitutions were found.

\section{Association between mtDNA varianats and hypertension}

Comparison of the frequency of variants in the 153 balanced cases and controls is presented in Table 2. Two single base pair changes were significantly $(P=0.01$ and $P=0.0001$,) different in the hypertensive patients and the controls: A8701G in ATP6 gene (threonine to alanine, belongs haplogroup M), and C8414T (LEUCINE to phenylalanine, belongs to haplogroup D) in ATP8 gene after adjusting age and gender. The results were consistent after adjusting more variables, including heart rate and body surface area. Frequency and type of the rest sequence variants did not differ significantly between cases and controls. The results remained unchanged when all the statistically significant variables in Table 1 were adjusted for. Interestingly, comparing 1 variant with $\geq 2$ variants, the hypertensives harbored more variants $(\geq 2)$ than the controls when amino-acid changes and RNAs variants were considered (57.43 versus $23.81 \%, P=0.0001$ ), as seen in Table 3.

\section{Discussion}

This is the first population-based report of a systematic screen for mitochondrial variants and their effect on Chinese Han essential hypertension. In our Chinese population, we found a substantial number of mitochondrial variants. Importantly, two amino-acid changes, A8701G in ATP6 gene (threonine to alanine) C8414T in

Table 1 Clinical manifestations of the hypertensives and the controls

\begin{tabular}{|c|c|c|c|}
\hline & Hypertensives $(\mathrm{n}=153)$ & Controls $(\mathrm{n}=153)$ & P-value \\
\hline Women, $n(\%)$ & $83(54)$ & $83(54)$ & 1.00 \\
\hline \multicolumn{4}{|l|}{ Age, years } \\
\hline At testing & $52.06 \pm 4.84$ & $50.99 \pm 15.96$ & 0.43 \\
\hline At onset & $46.46 \pm 6.87$ & & \\
\hline Body mass index, $\mathrm{kg} / \mathrm{m}^{2}$ & $24.32 \pm 2.20$ & $24.04 \pm 3.03$ & 0.36 \\
\hline Body surface area, $\mathrm{m}^{2}$ & $1.70 \pm 0.12$ & $1.70 \pm 0.19$ & 0.78 \\
\hline Systolic blood pressure, $\mathrm{mm} \mathrm{Hg}$ & $136.4 \pm 17.54$ & $120.56 \pm 12.03$ & $0.0001^{\mathrm{a}}$ \\
\hline Diastolic blood pressure, $\mathrm{mm} \mathrm{Hq}$ & $85.45 \pm 11.10$ & $75.06 \pm 7.81$ & $0.0001^{\mathrm{a}}$ \\
\hline Heart rate, b.p.m. & $71.56 \pm 7.79$ & $74.59 \pm 10.77$ & $0.005^{\mathrm{a}}$ \\
\hline Coronary heart disease, $n(\%)$ & $21(14)$ & $18(12)$ & 0.61 \\
\hline Cerebrovascular disease, $n(\%)$ & $4(3)$ & $2(1)$ & 0.41 \\
\hline Diabetes, $n(\%)$ & $26(17)$ & $28(18)$ & 0.77 \\
\hline Gout, $n(\%)$ & $17(11)$ & $8(5)$ & 0.06 \\
\hline Hyperlipidemia, $n(\%)$ & $94(61)$ & $82(54)$ & 0.17 \\
\hline Renal diseases, $n(\%)$ & $14(9)$ & $12(8)$ & 0.68 \\
\hline Alcohol, $n(\%)$ & $35(23)$ & $12(8)$ & $0.0002^{a}$ \\
\hline Smoking, $n(\%)$ & $30(20)$ & $15(10)$ & $0.02^{\mathrm{a}}$ \\
\hline Fasting blood glucose, $\mathrm{mmol} / \mathrm{l}$ & $5.44 \pm 1.18$ & $5.37 \pm 1.31$ & 0.65 \\
\hline Total cholesterol, $\mathrm{mmol} / \mathrm{l}$ & $4.96 \pm 0.91$ & $4.84 \pm 1.10$ & 0.32 \\
\hline Triglyceride, mmol/l & $1.63 \pm 1.00$ & $1.73 \pm 0.91$ & 0.35 \\
\hline High-density lipoprotein, $\mathrm{mmol} / \mathrm{l}$ & $1.35 \pm 0.30$ & $1.34 \pm 0.31$ & 0.66 \\
\hline Low-density lipoprotein, mmol/l & $2.81 \pm 0.74$ & $2.57 \pm 0.82$ & $0.007^{a}$ \\
\hline Blood urea nitrogen, $\mathrm{mmol} / \mathrm{l}$ & $5.38 \pm 1.83$ & $5.07 \pm 1.50$ & 0.11 \\
\hline Urea acid, $\mu \mathrm{mmol} / /$ & $323.89 \pm 69.58$ & $280.20 \pm 80.50$ & $0.0001^{\mathrm{a}}$ \\
\hline Creatinine, $\mu \mathrm{mmol} / /$ & $77.36 \pm 29.01$ & $70.67 \pm 46.87$ & 0.13 \\
\hline
\end{tabular}

${ }^{\mathrm{a}}$ Represents statistically significant. 
Table 2 Summary of mtDNA sequence analyses in the 153 hypertensives and 153 controls

\begin{tabular}{|c|c|c|c|c|c|c|c|c|c|}
\hline Position & Amino-acid change & Gene & Replacement & Conservation $\left(H / B / M / X^{\star \star}\right)$ & Previously reported & $E H$ & Controls & P-value & $\mathrm{P}^{\prime}$-value \\
\hline \multicolumn{10}{|l|}{ (A) } \\
\hline 3316 & Ala to Thr & ND1 & $G$ to $A$ & $\mathrm{~A} / \mathrm{I} / \mathrm{M} / \mathrm{I}$ & Yes & 1 & 1 & - & \\
\hline 3349 & Ile to Val & ND1 & $A$ to $G$ & $\mathrm{I} / \mathrm{L} / \mathrm{I} / \mathrm{L}$ & No & 1 & 0 & - & \\
\hline 3398 & Met to Thr & ND1 & $\mathrm{T}$ to $\mathrm{C}$ & $\mathrm{M} / \mathrm{M} / \mathrm{M} / \mathrm{M}$ & Yes & 2 & 0 & - & \\
\hline 3434 & Tyr to Cys & ND1 & A to $G$ & $\mathrm{Y} / \mathrm{Y} / \mathrm{Y} / \mathrm{Y}$ & Yes & 1 & 2 & - & \\
\hline 3497 & Ala to Val & ND1 & $C$ to $T$ & $\mathrm{~A} / \mathrm{A} / \mathrm{L} / \mathrm{S}$ & No & 2 & 0 & - & \\
\hline 3523 & Thr to Ala & ND1 & A to $\mathrm{G}$ & $\mathrm{T} / \mathrm{L} / \mathrm{I} / \mathrm{I}$ & No & 1 & 0 & - & \\
\hline 3866 & Ile to $\mathrm{Thr}$ & ND1 & $\mathrm{T}$ to $\mathrm{C}$ & $\mathrm{I} / \mathrm{I} / \mathrm{I} / \mathrm{I}$ & Yes & 1 & 0 & - & \\
\hline 4027 & lle to Val & ND1 & A to $G$ & $\mathrm{I} / \mathrm{L} / \mathrm{I} / \mathrm{L}$ & No & 2 & 0 & - & \\
\hline 4048 & Asp to Asn & ND1 & $G$ to $A$ & $\mathrm{D} / \mathrm{N} / \mathrm{Y} /{ }_{-}$ & Yes & 7 & 4 & 0.35 & 0.34 \\
\hline 4125 & lle to Met & ND1 & $A$ to $G$ & $\mathrm{I} / \mathrm{I} / \mathrm{I} / \mathrm{V}$ & No & 1 & 0 & - & \\
\hline 4136 & Tyr to Cys & ND1 & A to $G$ & $\mathrm{Y} / \mathrm{Y} / \mathrm{Y} / \mathrm{Y}$ & Yes & 1 & 1 & - & \\
\hline 4216 & Tyr to His & ND1 & $\mathrm{T}$ to $\mathrm{C}$ & $\mathrm{Y} / \mathrm{H} / \mathrm{H} / \mathrm{H}$ & Yes & 2 & 1 & - & \\
\hline 4485 & Gln to Lys & ND2 & $C$ to $A$ & $\mathrm{Q} / \mathrm{F} / \mathrm{L} / \mathrm{F}$ & No & 1 & 0 & - & \\
\hline 4491 & Val to lle & ND2 & $G$ to $A$ & $\mathrm{~V} / \mathrm{I} / \mathrm{I} / \mathrm{V}$ & Yes & 1 & 4 & - & \\
\hline 4554 & Thr to Ala & ND2 & A to $G$ & $\mathrm{~T} / \mathrm{V} / \mathrm{M} / \mathrm{A}$ & No & 1 & 0 & - & \\
\hline 8108 & Ile to Val & $\mathrm{CO} 2$ & A to $G$ & $\mathrm{I} / \mathrm{I} / \mathrm{I} / \mathrm{I}$ & Yes & 1 & 1 & - & \\
\hline 8414 & Leu to Phe & ATP8 & $\mathrm{C}$ to $\mathrm{T}$ & $\mathrm{L} / \mathrm{F} / \mathrm{M} / \mathrm{W}$ & Yes & 30 & 14 & $0.01^{*}$ & $0.01 *$ \\
\hline 8454 & Asn to Ser & ATP8 & A to $G$ & $\mathrm{~N} / \mathrm{K} / \mathrm{S} / \mathrm{K}$ & No & 0 & 1 & - & \\
\hline 8459 & Asn to Asp & ATP8 & $A$ to $G$ & $\mathrm{~N} / \mathrm{N} / \mathrm{T} / \mathrm{K}$ & No & 2 & 0 & - & \\
\hline 8466 & His to Arg & ATP8 & A to $G$ & $\mathrm{H} / \mathrm{Y} / \mathrm{P} / \mathrm{F}$ & No & $\overline{1}$ & 0 & - & \\
\hline 8547 & Leu to Pro & ATP8 & $\mathrm{T}$ to $\mathrm{C}$ & $\mathrm{L} / \mathrm{P} / \mathrm{P} /-$ & No & 2 & 0 & - & \\
\hline 8584 & Ala to $\mathrm{Thr}$ & ATP6 & $G$ to $A$ & $\mathrm{~A} / \mathrm{V} / \mathrm{V} / \mathrm{I}$ & Yes & $1 \overline{5}$ & 22 & 0.31 & 0.23 \\
\hline 8659 & Thr to Ala & ATP6 & A to $\mathrm{G}$ & $\mathrm{T} / \mathrm{L} / \mathrm{F} / \mathrm{L}$ & No & 1 & 0 & - & \\
\hline 8674 & Ile to Val & ATP6 & A to $\mathrm{G}$ & $\mathrm{I} / \mathrm{L} / \mathrm{V} / \mathrm{L}$ & No & 0 & 1 & - & \\
\hline 8684 & Thr to lle & ATP6 & $C$ to $T$ & $\mathrm{~T} / \mathrm{V} / \mathrm{l} / \mathrm{F}$ & No & 3 & 1 & - & \\
\hline 8701 & Thr to Ala & ATP6 & $A$ to $G$ & $\mathrm{~T} / \mathrm{S} / \mathrm{L} / \mathrm{Q}$ & Yes & 75 & 46 & $0.0001^{*}$ & $0.0001^{*}$ \\
\hline 8720 & Gly to Ala & ATP6 & $\mathrm{G}$ to $\mathrm{C}$ & $\mathrm{G} / \mathrm{G} / \mathrm{G} / \mathrm{G}$ & No & 1 & 0 & - & \\
\hline \multicolumn{10}{|l|}{ (B) } \\
\hline Position & RNAs & & Replacement & Conservation $\left(H / B / M / X^{\star *}\right)$ & Previously reported & $E H$ & Controls & P-value & $P^{\prime}$-value \\
\hline 3168 & 16SrRNA & & $\mathrm{C}$ to $\mathrm{CC}$ & $\mathrm{c} / \mathrm{t} / \mathrm{c} / \mathrm{t}$ & No & 1 & 0 & - & \\
\hline 3172 & 16SrRNA & & $\mathrm{C}$ to $\mathrm{CC}$ & $\mathrm{c} / \mathrm{g} / \mathrm{a} / \mathrm{t}$ & Yes & 1 & 0 & - & \\
\hline 3173 & 16SrRNA & & $G$ to $A$ & $\mathrm{~g} / \mathrm{a} / \mathrm{c} / \mathrm{a}$ & No & 1 & 0 & - & \\
\hline 3203 & 16SrRNA & & A to $G$ & $a / a / a / a$ & No & 2 & 0 & - & \\
\hline 3206 & 16SrRNA & & $\mathrm{C}$ to $\mathrm{T}$ & $\mathrm{c} / \mathrm{a} / \mathrm{t} / \mathrm{a}$ & Yes & 6 & 4 & 0.39 & 0.55 \\
\hline 3277 & tRNA $^{\text {Leu(UUR) }}$ & & $G$ to $A$ & $\mathrm{~g} / \mathrm{t} / \mathrm{c} / \mathrm{a}$ & Yes & 1 & 0 & - & \\
\hline 3290 & tRNA ${ }^{\text {Leu(UUR) }}$ & & $\mathrm{T}$ to $\mathrm{C} / \mathrm{T}$ & $\mathrm{t} / \mathrm{a} / \mathrm{a} / \mathrm{a}$ & No & 1 & 0 & - & \\
\hline 4263 & I & & $A$ to $G$ & $\mathrm{~A} / \mathrm{A} / \mathrm{A} / \mathrm{A}$ & No & 1 & 0 & - & \\
\hline 4316 & I & & $A$ to $T A$ & $\mathrm{~A} / \mathrm{A} / \mathrm{A} / \mathrm{A}$ & Yes & 1 & 0 & - & \\
\hline 4343 & $\mathrm{Q}$ & & $A$ to $G$ & $\mathrm{~A} / \mathrm{A} / \mathrm{A} /-$ & Yes & 1 & 0 & - & \\
\hline 4363 & Q & & $\mathrm{T}$ to $\mathrm{C}$ & $\mathrm{T} / \mathrm{T} / \mathrm{T} /-$ & No & 1 & 0 & - & \\
\hline 4386 & $\mathrm{Q}$ & & $\mathrm{T}$ to $\mathrm{C}$ & $\mathrm{T} / \mathrm{T} / \mathrm{A} /{ }_{-}$ & Yes & 5 & 2 & 0.22 & 0.25 \\
\hline 4410 & $M$ & & $C$ to $A$ & $\mathrm{C} / \mathrm{C} / \mathrm{C} / \mathrm{C}$ & No & 1 & 0 & - & \\
\hline 8311 & $\mathrm{~K}$ & & $\mathrm{~T}$ to $\mathrm{C}$ & $\mathrm{T} / \mathrm{T} / \mathrm{G} / \mathrm{L}_{-}$ & No & 1 & 0 & - & \\
\hline 8343 & $\mathrm{~K}$ & & A to $G$ & $\mathrm{~A} / \mathrm{C} / \mathrm{C} /-$ & Yes & 1 & 1 & - & \\
\hline 8347 & $\mathrm{~K}$ & & $A$ to $G$ & $\mathrm{~A} / \mathrm{A} / \mathrm{T} /-$ & Yes & 1 & 0 & - & \\
\hline
\end{tabular}

EH, essential hypertension; - represents the variants were too rare to be analyzed; *represents statistically significant. Two point mutations A8701G in ATP6 gene (threonine to alanine) $(P=0.0001)$, C8414T (leucine to phenylalanine) in ATP8 gene $(P=0.01)$ were statistically different after adjusting age, gender, heart rate and body surface area ( $P$-value), the results were consistent after adjusting for age and gender only ( $P^{\prime}$-value).

${ }^{*} \mathrm{H} / \mathrm{B} / \mathrm{M} / \mathrm{X}$ means human/bovine/mouse/xenopus.

ATP8 gene (leucine to phenylalanine) were different between cases and controls. These variants belong to haplogroup $\mathrm{D}^{20}$ (C8414T) and $\mathrm{M}^{21}$ (A8701G).These results provide evidence that mtDNA variants may affect the course of hypertension in Chinese populations.

In mtDNA, ancestral variants that define groups of types (haplogroups). Haplogroup, population-specific mtDNA lineages, was first initiated to trace back origins of different races and reconstruct ancient migration of women. ${ }^{22}$
Recently, the mtDNA lineages were reported more prone to specific symptoms of diseases, including atherothrombotic cerebral infarction, ${ }^{23}$ type- 2 diabetes ${ }^{24}$ and obesity. ${ }^{24}$ Meanwhile, haplogroups were found to protect individuals against myocardial infarction and attain longevity. ${ }^{21,25}$ In particular, mtSNP A8701G were identified altering mitochondrial matrix $\mathrm{pH}$ and intracellular calcium dynamics and suspected to be involved in pathogenesis of diseases. ${ }^{26}$ The base pair change $\mathrm{C}$ to $\mathrm{T}$ at position 8414 in ATP8 gene, 
Table 3 Variants' frequency per patient in the 153 hypertensives and 153 controls

\begin{tabular}{lcr}
\hline & 1 Variant & $\geq 2$ Variants \\
\hline Hypertensives & $43 / 101(42.57 \%)$ & $58 / 101(57.43 \%)$ \\
Controls & $48 / 63(76.19 \%)$ & $15 / 63(23.81 \%)$ \\
$P$-value & $0.0001^{\mathrm{a}}$ & \\
\hline
\end{tabular}

a Represents statistically significant, the above form indicates the frequency of amino-acid substitutions or RNA variants per patient; the result was the same even if all non-coding regions and synonymous changes were included.

part of the larger ATP synthase protein, may reduce the production of ROS and have the potential role to affect the course of hypertension.

In the cohort of hypertensives, there were several variants that occurred too infrequently to have sufficient statistical power, but that have biologic plausibility. T4363C localized at the $3^{\prime}$ end adjacent to the anticodon, which contributed to the stabilization of structure, and thus lead to the decrease of tRNA metabolism. A4263G at the initial part of tRNA ${ }^{\text {Ile }}$ may influence the transcription of tRNA herein affect the steady level of protein synthesis. And some other novel RNAs variants (C3168CC, G3173A, A3203G, T3290C, A4263G, T4363C, C4410A and T8311C) in 16s RNA, tRNA ${ }^{\mathrm{Leu}(U U \mathrm{UR})}, \mathrm{tRNA}^{\mathrm{Ile}}, \mathrm{tRNA}^{\mathrm{Met}}, \mathrm{tRNA}^{\mathrm{Gln}}$ and tRNA $^{\text {Lys }}$ were only found in hypertensives, but not controls. In coding regions, even though a novel point variant G8720C in ATP6 gene, with high conservation among species, was not significant in epidemiological perspective, they may affect the function of protein synthesis and need to be further investigated in the future.

One of the most surprising findings from the analyses using hypertension as the outcomes was that the hypertensive group was more likely to have $\geq 2$ mitochondrial variants than the controls, as seen in Table 3 . This novel finding would suggest that there may be a threshold effect with some of these mtDNA variants such that often variability at a single locus will not be sufficient to increase hypertension risk. This is consistent with work in the nuclear genome where it has been proposed that essential hypertension is controlled by multiple genetic loci, each with a relatively weak effect in the population at large; ${ }^{27-29}$ and compatible with synergistic pathogenic mutations of diseases that LHON was caused by 'primary mutation' and three mtSNPs called 'secondary mutations' in 11778,14484 and 3460 positions. $^{30}$ Otherwise, continent-specific mtDNA variants were prone to different diseases as described earlier. ${ }^{23,24,31}$ Thus, investigations on the synergistic interaction between mtSNPs and/or specific mtDNA lineages have been advocated by geneticists to date. ${ }^{22}$

In conclusion, mtSNPs in haplogroups $\mathrm{M}$ and $\mathrm{D}$ may affect the course of hypertension in sporadic Chinese hypertensives. Some specific mtSNP within mitochondria may have potential role in Chinese hypertensives due to their function. Synergetic interaction between mitochondrial $\mathrm{mtSNPs}$ and/or haplogroups is needed to be investigated in the future. This was the first step we marched to investigate the mitochondrial role in Chinese hypertensives. One potential limitation was the small sample size. The conclusion could have been made stronger if the number of people enrolled in the study had been greater.

\section{Acknowledgements}

We thank all the participants of investigation, sophisticated clinical data collection of Chunlin Zeng, experienced data analyzing of Xinyuan Tong.This study was supported by grants from Chinese National Natural Science Funds (Capital Developmental Grant-key project no.:2003-2019) and National Institutes of Health HL69712 (DWB).

\section{References}

1 Chobanian AV, Bakris GL, Black HR et al: The seventh report of the joint national committee on prevention, detection, evaluation, and treatment of high blood pressure: the JNC 7 report. JAMA 2003; 289: 2560-2572.

2 Liu LS: 2005 Guidelines for prevention and treatment of hypertension in China. Beijing: People's medical publishing house, 2007, pp $1-8$.

3 Harrap SB: Where are all the blood-pressure genes? Lancet 2003; 361: 2149-2151.

4 Bonnardeaux A, Davies E, Jeunemaitre X et al: Angiotensin II type 1 receptor gene polymorphisms in human essential hypertension. Hypertension 1994; 24: 63-69.

5 Caulfield M, Munroe P, Pembroke J et al: Genome-wide mapping of human loci for essential hypertension. Lancet 2003; 361: $2118-2123$.

6 Kamide K, Kokubo Y, Fukuhara S et al: Protein tyrosine kinase 2beta as a candidate gene for hypertension. Pharmacogenet Genomics 2007; 17: 931-939.

7 Banno M, Hanada H, Kamide $\mathrm{K}$ et al: Association of genetic polymorphisms of endothelin-converting enzyme-1 gene with hypertension in a Japanese population and rare missense mutation in preproendothelin-1 in Japanese hypertensives. Hypertens Res 2007; 30: 513-520.

8 Kulah E, Dursun A, Aktunc E et al: Effects of angiotensinconverting enzyme gene polymorphism and serum vitamin D levels on ambulatory blood pressure measurement and left ventricular mass in Turkish hypertensive population. Blood Press Monit 2007; 12: 207-213.

9 Wallace DC: Mitochondrial diseases in man and mouse. Science 1999; 283: $1482-1488$.

10 Hirano M, Davidson M, DiMauro S: Mitochondria and the heart. Curr Opin Cardiol 2001; 16: 201-210.

11 Lassègue $B$, Griendling KK: Reactive oxygen species in hypertension; an update. Am J Hypertens 2004; 17: 852-860.

12 Hutchinson J, Crawford MH: Genetic determinants of blood pressure level among the Black Caribs of St Vincent. Hum Biol 1981; 53: $453-466$.

13 DeStefano AL, Gavras H, Heard-Costa N et al: Maternal component in the familial aggregation of hypertension. Clin Genet 2001; 60: $13-21$.

14 Yang Q, Kim SK, Sun F et al: Maternal influence on blood pressure suggests involvement of mitochondrial DNA in the pathogenesis of hypertension: the Framingham Heart Study. J Hypertens 2007; 25: 2067-2073.

15 Wilson FH, Hariri A, Farhi A et al: A cluster of metabolic defects caused by mutation in a mitochondrial tRNA. Science 2004; 306: $1190-1194$ 
16 Zhu H, Wang S: Mitochondria and left ventricular hypertrophy. J Geriatr Cardiol 2008; 5: 50-59.

17 Anderson S, Bankier AT, Barrell BG et al: Sequence and organization of the human mitochondrial genome. Nature 1981; 290: $457-465$.

18 Ingman M, Gyllensten U: mtDB: Human mitochondrial genome database, a resource for population genetics and medical sciences. Nucleic Acids Res 2005; 34: 749-751.

19 Ruiz-Pesini E, Lott MT, Procaccio V et al: An enhanced MITOMAP with a global mtDNA mutational phylogeny. Nucleic Acids Res 2007; 35: 823-828.

20 Herrnstadt C, Elson JL, Fahy E et al: Reduced-median-network analysis of complete mitochondrial DNA coding-region sequences for the major African, Asian, and European haplogroups. Am J Hum Genet 2002; 70: 1152-1171.

21 Nishigaki Y, Yamada Y, Fuku N et al: Mitochondrial haplogroup $\mathrm{N} 9 \mathrm{~b}$ is protective against myocardial infarction in Japanese males. Hum Genet 2007; 120: 827-836.

22 Wallace DC: Mitochondrial DNA sequence variation in human evolution and disease. Proc Natl Acad Sci USA 1994; 91: 8739-8746.

23 Nishigaki Y, Yamada Y, Fuku N et al: Mitochondrial haplogroup A is a genetic risk factor for atherothrombotic cerebral infarction in Japanese females. Mitochondrion 2007; 7: 72-79.

24 Guo LJ, Oshida Y, Fuku $\mathrm{N}$ et al: Mitochondrial genome polymorphisms associated with type-2 diabetes or obesity. Mitochondrion 2005; 5: 15-33.
25 Dato S, Passarino G, Rose G et al: Association of the mitochondrial DNA haplogroup J with longevity is population specific. Eur J Hum Genet 2004; 12: 1080-1082.

26 Kazuno AA, Munakata K, Nagai $\mathrm{T}$ et al: Identification of mitochondrial DNA polymorphisms that alter mitochondrial matrix $\mathrm{pH}$ and intracellular calcium dynamics. PLoS Genet 2006; 2: e128.

27 Rice T, Rankinen T, Province MA et al: Genome-wide linkage analysis of systolic and diastolic blood pressure: the Quebec Family Study. Circulation 2000; 102: 1956-1963.

28 Yang Z, Venardos $\mathrm{K}$, Jones $\mathrm{E}$ et al: Identification of a novel polymorphism in the $3^{\prime}$ UTR of the L-arginine transporter gene SLC7A1: contribution to hypertension and endothelial dysfunction. Circulation 2007; 115: 1269-1274.

29 Amamoto K, Okamura T, Tamaki S et al: Epidemiologic study of the association of low-Km mitochondrial acetaldehyde dehydrogenase genotypes with blood pressure level and the prevalence of hypertension in a general population. Hypertens Res 2002; 25: 857-864.

30 Lodi R, Montagna P, Cortelli P et al: 'Secondary' 4216/ND1 and 13708/ND5 Leber's hereditary optic neuropathy mitochondrial DNA mutations do not further impair in vivo mitochondrial oxidative metabolism when associated with the 11778/ND4 mitochondrial DNA mutation. Brain 2000; 123: 1896-1902.

$31 \mathrm{Xu} \mathrm{L}, \mathrm{Hu} \mathrm{Y}$, Chen B et al: Mitochondrial polymorphisms as risk factors for endometrial cancer in southwest China. Int J Gynecol Cancer 2006; 16: 1661-1667. 